\title{
Patterns of diseases and preventive measures among domestic hajjis from Central, Saudi Arabia [complete republication]
}

\author{
Fahad S. Al-Jasser, Ibrahim A. Kabbash, Mohammad A. AlMazroa, Ziad A. Memish
}

$$
\begin{aligned}
& \text { الخلاصـة: الأهدافو: تحديد معدل حدوث أمراض الجهاز التنفسي العلوي والإسهال والإصابات أثناء موسم الحجج والإجر اءات الوقائية المتبعة بين }
\end{aligned}
$$

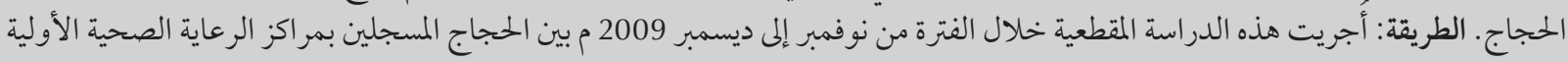

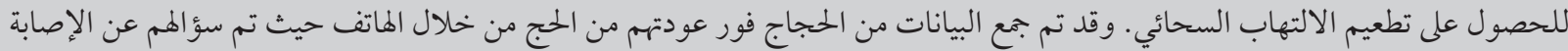

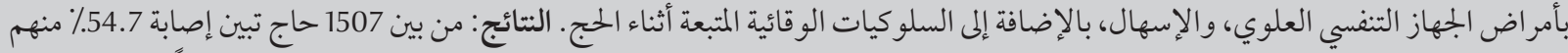

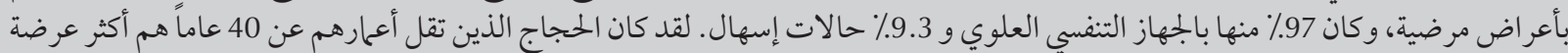

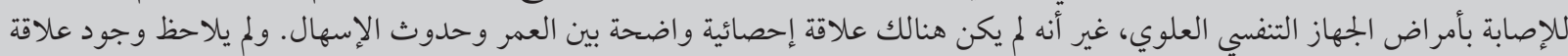

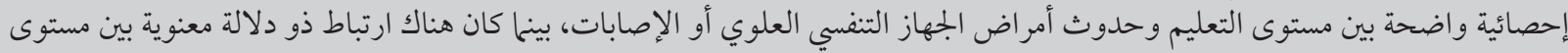

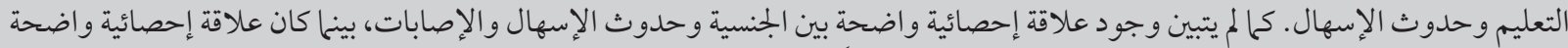

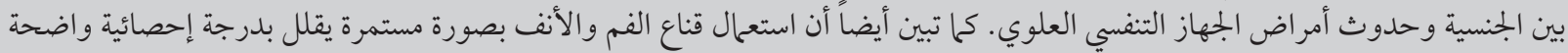

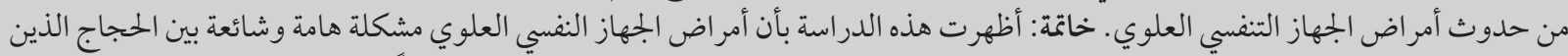

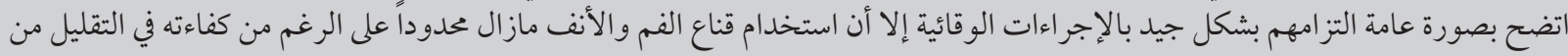

$$
\begin{aligned}
& \text { حدوث الإصابة بأمر اض الجهاز التنفسي العلوي. }
\end{aligned}
$$

ABSTRACT Objectives: To identify the occurrence of upper respiratory tract infections (URTI), diarrheal diseases and trauma during the Hajj season, and the practice of some preventive measures by pilgrims. Methods: A cohort study during November and December 2009 among hajjis registered while visiting Primary Health Care Centers of Riyadh, Kingdom of Saudi Arabia to get mandatory meningococcal meningitis vaccination. On return from hajj, hajjis were contacted on telephone to collect information on occurrence of URTI and diarrhea along with other associated activities in Hajj. Results: Out of 1507 hajjis, 54.7\% developed symptoms; $97 \%$ reported upper respiratory tract symptoms, and $9.3 \%$ reported diarrheal symptoms. Those $<40$ years of age were more likely to develop an URTI. The incidence of diarrheal diseases or trauma was not statistically associated with age. No statistical difference for educational level was found for URTI or trauma, but there was a statistically significant difference for diarrheal diseases. There was no statistical difference for nationality in relation to diarrheal diseases and trauma, but there was a statistically significant difference for URTI. There was a statistically significant difference of URTI between those pilgrims who used the face mask most of the time and those who used it sometimes. Conclusion: Upper respiratory tract infections is a common health problem among studied domestic hajjis. Generally, there is room for improvement in the adoption of preventive measures by hajjis; and there is still limited information on the use of facemasks in spite of the fact that using it significantly decreases the risk for URTI.

From the Field Epidemiology Training Program (Al-Jasser, AlMazroa, Memish), Ministry of Health, Riyadh, Kingdom of Saudi Arabia and the Public Health and Community Medicine Department (Kabbash), Faculty of Medicine, Tanta University, Tanta, Egypt (iakabbash@gmail.com).

This paper was first published in the Saudi Medical Journal, 2012, 33(8):879-886 and is reproduced here with kind permission of the Saudi Medical Journal. It is included in this supplement because the paper arose from one of the studies undertaken by the "Surveillance in Mass Gathering Workshops" for Field Epidemiology Training Program Residents and graduates under the mentorship of Centers for Disease Control and Prevention (CDC)/Eastern Mediterranean Public Health Network (EMPHNET) experts. 


\section{Introduction}

Hajj (pilgrimage) is a yearly event in which more than 2 million Muslims from around the world gather in Mecca, Saudi Arabia. It is the largest annual gathering of its kind in the world bringing millions of people in a small and geographically confined area. All adult Muslims who are physically and financially able to do so have a religious obligation to make the pilgrimage once in their lifetime. The limited time and space in which this mass gathering takes place exposes these hajjis to several risk factors [1]. Overcrowding increases the chances of trauma and transmission of communicable diseases. Transportation to the Hajj area is mainly through air for international hajjis. Domestic hajjis can reach the Hajj area either by air or surface transport, which is a cheaper mode of transport. Hajjis can use buses for transport within the Hajj area or can move around on foot. In this Hajj season, the services of train transportation between key locations in the Hajj area were made available. A hamla is a company that is specialized in Hajj services. These hamlas are responsible for travel arrangements, accommodation and food arrangements for every hajji who paid for their services [2-5]. The changing of Hajj season from summer to winter changes the pattern of diseases that are detected among hajjis. Since Hajj season has changed in the last few years from summer to winter, diseases that were seen in summer season (such as heat stroke, food poisoning and exhaustion) are not seen anymore [6]. In Hajj season diseases are expected to be more common such as influenza, asthma and chronic obstructive pulmonary disease. During Hajj rituals, hajjis are exposed to several health risks. Physical exertion is a health risk itself and it can aggravate pre-existing health conditions (such as diabetes mellitus, cardiovascular and renal disease) $[2,4]$. During animal slaughter, as part of Hajj rituals the risk of exposure to zoonotic diseases is increased [7]. Another Hajj ritual which poses a health risk is head shaving for men. Head shaving is performed with razors or blades which if used without changing for several hajjis can transmit blood borne infections ( HIV, hepatitis $B$ and hepatitis C) [8]. Many Hajj studies showed a change in the pattern of diseases detected among hajjis from infectious diseases to chronic diseases [9-11]. Mina is a key place in the Hajj area. It is where the hajji spends the most of the time in the Hajj season (at least 4 days). This relatively long duration account for the burden on health services in this area. Many researchers studied pattern of diseases among hajjis visiting Mina hospitals. Those cases that reach hospitals are usually the tip of the iceberg and they are mostly advanced stages of the disease, which can be less representative to the real Hajj population [5,12-14]. Currently there is no surveillance system for some hajj-related and post hajj illnesses. The primary objectives of this study were to assess the incidence of selected diseases and injuries among hajjis and to use this information by the Ministry of Health $(\mathrm{MOH})$ for future surveillance of specified conditions at the Hajj, and to assess preventive measures practiced by hajjis. Specific conditions of interest included upper respiratory tract illnesses (URTI), diarrhoeal illnesses, and injuries.

\section{Methods}

\section{Study setting}

This cohort study was conducted during November and December 2009 in Riyadh City, the capital of Saudi Arabia with a population of nearly 5 million. Since there is no common station to identify and recruit hajjis returning to Riyadh from Hajj, subjects were recruited as they sought their required pre-Hajj meningococcal vaccination.
Riyadh City has 87 primary health care centres (PHCC) that give meningococcal vaccination as an obligatory requirement for those who will perform the Hajj. These PHCC are distributed in 7 health sectors. The number of PHCCs in each health sector ranges from 7-20 centres. Therefore, the study population consisted of all adults older than 20 years of age living in Riyadh City with the intention to perform the Hajj in 2010, who sought their required meningococcal immunization at a PHCC. Vaccinations started on 16th October 2010 and continued on daily basis until 7 November 2010, which was the first day in the Hajj season.

\section{Case definition}

For the purpose of this study, URTI was defined as any person who reported having developed at least one of the constitutional symptoms (fever, headache, myalgia) and one of the local symptoms (running nose, sneezing, throat pain, cough with / or without sputum) after reaching Makkah for the Hajj or within 2 weeks from return to Riyadh [15]. Diarrhoea was defined as the passage of 3 or more loose or liquid stools per day after reaching Makkah for the Hajj or within 2 days from return to Riyadh to ensure that diarrhoea infection was acquired during hajj period not after return home.

\section{Sampling}

A 2 stage sampling technique was used. In the first stage, Riyadh City was stratified into 7 strata according to the number of health sectors. Simple random sampling of 1-2 PHCC from each stratum was carried out according to the number of PHCC in each health sector. From health sectors with 10 or fewer PHCC, one PHCC was selected. Two PHCC were randomly selected from health sectors with more than 10 PHCC, resulting in a total of 11 centres. In the second stage, study subjects were systematically selected from each of the 11 centres by selecting every third 
person seeking meningococcal vaccination for their Hajj requirement.

A sample size of 1499 was calculated using Epi-Info version 3.5.1 to estimate diseases with proportion of $1 \%$ or more in the study sample with a precision of $0.5 \%$ at $95 \%$ confidence level; and was then increased to 1804 to account for the anticipated non-responders.

Recruits were asked to give their contact information and consent at the time of recruitment so that they could be contacted 48 hours upon return from the Hajj up to a period of 4 weeks after return. A standardized phone-based questionnaire regarding selected illnesses (which include diabetes, hypertension, cardiac diseases, renal diseases and bronchial asthma), injuries, and preventive measures was developed and pilot-tested prior to administering it to returning hajjis. Three trained interviewers contacted participants during working hours, with follow-up calls at other times to improve the response. Those who were not contacted after 4 days of attempts were classified as nonresponders and were excluded.

\section{Statistical analysis}

The collected data were organized, tabulated, and statistically analysed using SPSS software statistical package version 19 . The number and percentage distribution for each variable was calculated. Observed differences were statistically analysed using Chi square test and risk estimation was carried out using relative risk and 95\% confidence intervals. The level of significance was adopted at $P<0.05$.

\section{Results}

Out of 1804 initial enrolled, 1507 Hajj pilgrims responded and were included into the study. Males predominated the study population $(61.7 \%)$. The mean age was $37.9 \pm 12.1$ years with a range of 21-83 years of age. The main nationalities were Saudi and Arabs
(84.5\%). Hajjis from South Asia comprised $7.4 \%$, South East Asia 4.9\%, and Africa $3.2 \%$ of the study population. Half of the study population (49.5\%) had a university education, including Master's and Doctorate degrees. The occupational status of study participants was reported as $31.4 \%$ unemployed, $13.7 \%$ manual workers, $21.4 \%$ employee, $21.3 \%$ professional, $3.8 \%$ retired, $4.9 \%$ were students, and $3.5 \%$ self employed. All participants were vaccinated for meningococcal meningitis. Some hajjis received vaccines upon their request other than meningococcal meningitis $(n=218)$; $5.9 \%$ were vaccinated against Hepatitis A, 6.4\% against Hepatitis B, and $94.4 \%$ were vaccinated for seasonal flu (categories not mutually exclusive). Different modes of travel to Makkah were available; $50.6 \%$ of hajjis travelled by bus, $20.2 \%$ by plane and $29.2 \%$ by car. The travel coordination services of a Hamla were utilized by nearly all Hajjis (95.7\%). The average length of stay at the Hajj (Makkah and Mina) was $7.04 \pm 1.78$ days and all but 2 pilgrims were able to complete the Hajj.

Illness symptoms were reported by 825 (54.7\%) of the returning Hajjis. These symptoms were used to categorize participants into disease groups. Of the 825 reporting symptoms, 97\% reported upper respiratory tract symptoms (53\% of total studied group), and 9.3\% reported diarrhoeal symptoms ( $5.1 \%$ of total studied group) (not mutually exclusive). Of the 825 with symptoms, $51 \%$ reported contact with a person having similar symptoms and $43.2 \%$ sought medical care at a health care facility whether during hajj or upon return home. Traumatic injuries were reported by $2.9 \%$ (Table 1 ).

Face masks were used by 851 (56.5\%) of participants. Of those, 216 (25.4\%) reported using it most of the time and 635 (74.6\%) reported using it sometimes. Of the 577 females in the study population, $333(57.7 \%)$ reported

\begin{tabular}{|c|c|c|}
\hline Health problems in Hajj & $\mathbf{n}$ & $\%$ \\
\hline \multicolumn{3}{|l|}{ Having symptoms: $n=1507$} \\
\hline Yes & 825 & 54.7 \\
\hline No & 682 & 45.3 \\
\hline \multicolumn{3}{|l|}{ Diseases $^{a} n=825$} \\
\hline URTI & 800 & 97.0 \\
\hline Diarrheal diseases & 77 & 9.3 \\
\hline Others $^{\mathrm{b}}$ & 16 & 1.9 \\
\hline \multicolumn{3}{|l|}{ Contact with similar case: $n=825$} \\
\hline Yes & 421 & 51.0 \\
\hline No & 259 & 31.4 \\
\hline Do not know & 145 & 17.6 \\
\hline Visited any health care facility: $n=825$ & 356 & 43.2 \\
\hline Trauma: $n=1507$ & 44 & 2.9 \\
\hline \multicolumn{3}{|l|}{ Type of trauma: $n=44$} \\
\hline Fractures & 1 & 2.3 \\
\hline Cut wounds & 16 & 36.4 \\
\hline Contusions & 13 & 29.5 \\
\hline Strain & 14 & 31.8 \\
\hline
\end{tabular}

${ }^{a}$ More than one disease were sometimes reported.

${ }^{b}$ Allergy, chest pain, hemorrhoids, joint pain, blocked nose, neck pain, sinusitis, sputum, URTI - upper respiratory tract illnesses. 


\begin{tabular}{|c|c|c|}
\hline Preventive measures & $\mathbf{n}$ & $\%$ \\
\hline \multicolumn{3}{|l|}{ Face mask $(n=1507)$} \\
\hline Most of the time & 216 & 14.3 \\
\hline Sometimes & 368 & 24.4 \\
\hline Occasionally & 267 & 17.7 \\
\hline Never & 656 & 43.5 \\
\hline \multicolumn{3}{|l|}{ Face cover $(n=577)$} \\
\hline Most of the time & 300 & 52.0 \\
\hline Sometimes & 25 & 4.3 \\
\hline Occasionally & 8 & 1.4 \\
\hline Never & 244 & 42.3 \\
\hline \multicolumn{3}{|l|}{ Eat usually $(n=1507)$} \\
\hline Street vendor & 272 & 18.0 \\
\hline Hamla & 1109 & 73.6 \\
\hline Self cooked food & 126 & 8.4 \\
\hline Eat raw food/vegetables: $(n=1507)$ & 1265 & 83.9 \\
\hline \multicolumn{3}{|l|}{ Shaved head $(n=930)$} \\
\hline Did not shave & 375 & 40.3 \\
\hline Shaved: & 555 & 59.7 \\
\hline By licensed barber & 392 & 70.6 \\
\hline By unlicensed barber & 56 & 10.1 \\
\hline By another hajji & 107 & 19.3 \\
\hline Ask for new blade & 532 & 95.9 \\
\hline Scalp wounds & 126 & 13.5 \\
\hline Animal slaughter: $(n=930)$ & 11 & 1.2 \\
\hline \multicolumn{3}{|l|}{ Hand washing $(n=1507)$} \\
\hline Less than 5 times/day & 146 & 9.7 \\
\hline More than 5 times/day & 1361 & 90.3 \\
\hline Using hand sanitizer: $(n=1507)$ & 686 & 45.5 \\
\hline \multicolumn{3}{|l|}{ Source of drinking water $(n=1507)$} \\
\hline Bottled water & 1340 & 88.9 \\
\hline Shared water & 41 & 2.7 \\
\hline Public water & 334 & 22.2 \\
\hline Smoking $(n=1507)$ & 307 & 20.4 \\
\hline
\end{tabular}

More than one source of drinking water were reported.

wearing a face cover and $90.1 \%$ reported wearing it most of the time while 33 (9.9\%) wore it sometimes. Food service was provided by a Hamla for $73.6 \%$; the remainder reported consuming self cooked meals (8.4\%) and food from street vendors (18.0\%). Consumption of raw food or vegetables from any source was reported by $83.9 \%$ and most used bottled water for drinking during participation in the Hajj (88.9\%). (Table 2).
Nearly half of the hajjis used hand sanitizer during Hajj (45.5\%). None of the females reported smoking, and among males, 307 (33.3\%) were smokers (Table 2).

Selected chronic diseases were reported by 278 (18.4\%) of study participants. Of those, diabetes was reported in $55.7 \%$, hypertension in $60.7 \%$, other cardiac disease (7.5\%), and bronchial asthma (11.5\%) (not mutually exclusive). Hajjis who had a chronic disease were using their medications regularly (82.0\%); of those with a chronic disease, $89.2 \%$ reported that they had enough supply of their medications (Table 3). Gender was found to be significantly associated with the occurrence of diarrhoea were males reported an incidence of $6.3 \%$ compared to $3.1 \%$ for females ( $\mathrm{RR}=2.03, P=0.006)$. On the other hand, nationality (whether Saudi or non-Saudi) did not affect the risk of diarrhoea. The incidence of diarrhoea was highest among hajjis who stayed 4 days or less (11.5\%). Longer durations of stay were found to have lower risk for diarrhoea, which was lowest for those 7 days of stay where the incidence was reported to be $2.9 \%(\mathrm{RR}=0.25, P=0.021)$. Source of food, eating raw vegetables, frequency of hand washing and use of hand sanitizers did not significantly affect the incidence of diarrhoea among studied hajjis (Table 4). Gender, nationality whether Saudi or non-Saudi did not show significant effect on risk of occurrence of URTI. The incidence of UTRIs significantly increased with increased level of education where it was highest among those with primary education ( $R R=1.65, P=0.002)$. Concerning duration of stay in hajj areas, those who stayed 8 days or more were significantly suffering from lower risk of infection ( $R R=0.78, P=0.006$ ) compared to other hajjis spending shorter periods. Never or sometimes using face mask was found to significantly increase the risk for URTI ( $R R=1.17$ and $\mathrm{RR}=1.21$ ) compared to those who used it most of times. On the other hand, 


\begin{tabular}{lcc}
\hline Table 3 Distribution of chronic diseases among & \multicolumn{3}{c}{ domestic hajjis from Riyadh } \\
Chronic diseases & $\mathbf{n}$ & $\%$ \\
Any chronic disease $(\mathrm{n}=1507)$ & 278 & 18.4 \\
Type of chronic diseases $(\mathrm{n}=278)$ & & \\
$\quad$ Diabetes & 155 & 55.7 \\
$\quad$ Hypertension & 169 & 60.7 \\
$\quad$ Cardiac diseases & 21 & 7.5 \\
Bronchial asthma & 32 & 11.5 \\
$\quad$ Renal diseases & 1 & 0.3 \\
Having exacerbations of current disease $(\mathrm{n}=278)$ & 79 & 28.4 \\
Diabetics ( $\mathrm{n}=155)$ & 50 & 32.2 \\
Hypertensive's $(\mathrm{n}=169)$ & 57 & 33.7 \\
Using medications regularly during Hajj $(\mathrm{n}=278)$ & 228 & 82.0 \\
Have enough supply of medications during Hajj & & \\
$(\mathrm{n}=278)$ & 248 & 89.2 \\
\hline
\end{tabular}

Types of chronic diseases were not mutually exclusive.

the use of face cover was not found to significantly decrease the risk of infection (Table 5).

\section{Discussion}

Acute respiratory tract infections, diarrhoeal diseases and injuries occur worldwide throughout the year and are not limited to any specific age, gender, or nationality. For example, several factors contribute to the wide spread of URTIs including direct contact with affected person, change in climate, and crowded places; all of these contributing factors are present in the Hajj environment [16]. Significant proportion (53\%) of hajjis from Riyadh reported experiencing an URTI during or immediately after the Hajj. This high incidence of an illness reveals a high burden of disease. While outside the scope of this study, potential secondary spread among the susceptible population in the hometown of returning hajjis can occur. The disease is uniformly distributed between both genders both old age and diabetes mellitus is known to reduce the immunity and increase the risk for URTIs and other viral infections. The reduced risk between these 2 groups can be due to the reduced mobility of these groups making them less exposed to URTI cases [11]. The present study showed that those who stayed more than 8 days suffered less URTIs. This could be explained by the fact that hajjis who tend to spend shorter periods were in hurry to perform all rituals during the rush time, which increases the physical burden and possibility of getting spending a relatively longer duration had more opportunity to avoid periods of overcrowdings and perform rituals relatively more comfortably.

As in many mass gatherings, it is important to understand how to prevent the occurrence of a heavy burden of URTI. Given the circumstances of Hajj,it is almost impossible to adequately control the spread of illnesses, facilitated by crowding. The use of personal protective measures such as vaccination,chemoprophylaxis, frequent hand washing/sanitizing,and the use of a face mask provide some protection [15].

Use of a face mask in our study population, was the most important practical protective factor against development of an URTI, although the research evidence regarding the effectiveness of face masks does not include consensus agreement. The use of face masks has been advocated to protect infected. On the other hand those from inhalation of aerosols containing organic and inorganic particulates [17]. Therefore, as a preventive measure,the recommendations for the prevention of influenza include wearing face mask [18].Although wearing mask may not provide complete protection from infection; it may reduce exposure to droplet nuclei, considered one of the main modes of transmission of most URTIs [18]

The use offace cover (Hijab/Niqab) by women can also be treated as use of face mask. As most of the female hajjis were Saudis, who practices face cover more often during Hajj as compared to other nationalities, the usage of face mask was quite frequent. But there was no evidence of significant decrease in the incidence of URTI, among women in the present study related to using face mask or face cover. This difference from males can be explained on the basis of other customary practices. Women when alone in their tents with other females do not cover their face (as the use is meant mainly for Hijab and not for personal hygiene) thus having the same high risk of disease transmission in a closed environment with exposure to droplet infection. Thus, the use of face cover as proxy of face mask in status. This change of practice within tents may not be so prominent in men, who are using face mask as personal hygiene measure, independent of the place where they were.

In this study, $9.3 \%$ of hajjis from Riyadh who reported symptoms had an attack of diarrhoeal disease during or immediately after the Hajj. The high risk of diarrhoea among males could be explained by the liability of males to get food from different sources due to their wide range of movement compared to females who are usually in the tents most of the time. The Hajj season this year was in the month of November, which means that the weather was cool and that was not in favour of food born diseases. Also, most of the study participants ate food prepared by a Hamla 


\begin{tabular}{|c|c|c|c|c|c|c|}
\hline Source of food & $\begin{array}{l}\text { Total hajjis } \\
(\mathrm{n}=1507)\end{array}$ & $\begin{array}{c}\text { Cases of } \\
\text { diarrhoea } \\
(n=77)\end{array}$ & Incidence (\%) & Relative risk & $\begin{array}{l}95 \% \text { confidence } \\
\text { interval }\end{array}$ & $P$-value \\
\hline \multicolumn{7}{|l|}{ Gender } \\
\hline Male & 930 & 59 & 6.3 & 2.03 & $1.21-3.41$ & 0.006 \\
\hline Female & 577 & 18 & 3.1 & 1 & & \\
\hline \multicolumn{7}{|l|}{ Nationality } \\
\hline Saudi & 610 & 31 & 5.1 & 1 & & \\
\hline Non-Saudi & 897 & 46 & 5.1 & 1.01 & $0.65-1.57$ & 0.968 \\
\hline \multicolumn{7}{|l|}{ Educational level } \\
\hline Illiterate & 53 & 2 & 3.8 & 1 & & \\
\hline Primary school & 159 & 4 & 2.5 & 0.67 & $0.13-3.54$ & 0.632 \\
\hline Intermediate school & 188 & 8 & 4.3 & 1.13 & $0.25-5.15$ & 0.876 \\
\hline High school & 362 & 12 & 3.3 & 0.88 & $0.20-3.82$ & 0.863 \\
\hline University & 745 & 51 & 6.8 & 1.81 & $0.45-7325$ & 0.385 \\
\hline \multicolumn{7}{|c|}{ Duration of stay in Hajj area in days } \\
\hline$<4$ & 26 & 3 & 11.5 & 1 & & \\
\hline 5 & 144 & 8 & 5.6 & 0.48 & $0.14-1.70$ & 0.254 \\
\hline 6 & 520 & 28 & 5.4 & 0.47 & $0.15-1.44$ & 0.186 \\
\hline 7 & 344 & 10 & 2.9 & 0.25 & $0.07-0.86$ & 0.021 \\
\hline$>8$ & 473 & 28 & 5.9 & 0.51 & $0.17-1.58$ & 0.248 \\
\hline \multicolumn{7}{|l|}{ Source offood } \\
\hline Street vendor & 272 & 13 & 4.8 & 1 & & \\
\hline Hamla & 1109 & 58 & 5.2 & 1.09 & $0.61-1.97$ & 0.763 \\
\hline Self cooked food & 126 & 6 & 4.8 & 1.00 & $0.39-2.56$ & 0.994 \\
\hline Eat raw vegetable & & & & & $0.59-1.90$ & 0.840 \\
\hline Yes & 1265 & 64 & 5.1 & 1 & & \\
\hline No & 242 & 13 & 5.4 & 1.06 & & \\
\hline \multicolumn{7}{|l|}{ Hand washing } \\
\hline$<5$ times/day & 146 & 8 & 5.5 & 1 & & \\
\hline$>5$ times/day & 1361 & 69 & 5.1 & 0.93 & 0.45-1.89 & 0.831 \\
\hline \multicolumn{7}{|l|}{ Use of hand sanitizer } \\
\hline Yes & 686 & 42 & 6.1 & 1 & & \\
\hline No & 821 & 35 & 4.3 & 0.70 & $0.45-1.08$ & 0.103 \\
\hline
\end{tabular}

The reference group is the one with relative risk $=1$.

and drank bottled water. Nearly half of the studied hajjis were using hand sanitizers and mostly was washing their hands more than 5 times per day. The high percentage of diarrhoea among those with high educational level may be contributed to their chance to live in better housing conditions and neighbourhood compared to those with low educational level and low income. At hajj, and due to overcrowdings, the environment suffers much from pollution which can be relatively tolerated better by the low educated who may be exposed to similar conditions at their homes while the highly educated cannot leading to their more suffering from diarrhoea

In the present study, more than half of the hajjis had used the razor blades to shave their head during hajj. Head shaving exposes hajjis to scalp wounds especially in case of unexperienced barbers, hastiness due to rush or the hajjis shaving for each other. Due to inability to find barber shops and their crowdedness, hajjis were forced to rely on other hajjis for head shaving or hair cutting, which gave a good chance for the unlicensed mobile barbers to be active or hajjis learning head shaving on their fellow hajjis with increased risks of cuts. Less than $15 \%$ of hajjis who get their head shaved were aware of having at least one cut wound in their scalps. Excessive scalp wounds with the added risk of poor personal hygiene create ideal environment for skin infections and wound contaminations. It is good 


\begin{tabular}{|c|c|c|c|c|c|c|}
\hline Source of food & $\begin{array}{l}\text { Total hajjis } \\
(\mathbf{n}=1507)\end{array}$ & $\begin{array}{l}\text { Cases of URTI } \\
\quad(\mathbf{n}=\mathbf{8 0 0})\end{array}$ & Incidence (\%) & Relative risk & $\begin{array}{l}\text { 95\% confidence } \\
\text { interval }\end{array}$ & $P$-value \\
\hline \multicolumn{7}{|l|}{ Gender } \\
\hline Male & 930 & 483 & 51.9 & 1 & & \\
\hline Female & 577 & 317 & 54.9 & 1.06 & $0.96-1.16$ & 0.256 \\
\hline \multicolumn{7}{|l|}{ Nationality } \\
\hline Saudi & 610 & 326 & 53.44 & 1 & & \\
\hline Non-Saudi & 897 & 474 & 52.84 & 0.99 & 0.90-1.09 & 0.819 \\
\hline \multicolumn{7}{|l|}{ Educational level } \\
\hline Illiterate & 53 & 20 & 37.73 & 1 & & \\
\hline Primary school & 159 & 99 & 62.26 & 1.65 & $1.14-2.38$ & 0.002 \\
\hline Intermediate school & 188 & 99 & 52.65 & 1.40 & $0.96-2.02$ & 0.055 \\
\hline High school & 362 & 190 & 52.48 & 1.39 & 0.97-1.99 & 0.045 \\
\hline University & 745 & 392 & 52.61 & 1.39 & 0.98-1.98 & 0.036 \\
\hline \multicolumn{7}{|c|}{$\begin{array}{l}\text { Duration of stay in Hajj area in } \\
\text { days }\end{array}$} \\
\hline$<4$ & 26 & 14 & 53.84 & 1 & & \\
\hline 5 & 144 & 84 & 58.33 & 1.08 & $0.74-1.59$ & 0.670 \\
\hline 6 & 520 & 296 & 56.92 & 0.98 & $0.83-1.14$ & 0.762 \\
\hline 7 & 344 & 192 & 55.81 & 0.96 & $0.81-1.13$ & 0.609 \\
\hline$>8$ & 473 & 214 & 45.24 & 0.78 & $0.65-0.92$ & 0.006 \\
\hline \multicolumn{7}{|l|}{ Used face mask } \\
\hline Most of the time & 216 & 98 & 45.37 & 1 & & \\
\hline Sometimes & 635 & 341 & 53.70 & 1.17 & $1.00-1.38$ & 0.045 \\
\hline Never & 656 & 361 & 55.03 & 1.21 & $1.03-1.43$ & 0.014 \\
\hline \multicolumn{7}{|c|}{ Used face cover (Hijab/Niqab)* } \\
\hline Most of the time & 300 & 164 & 54.66 & 1 & & \\
\hline Sometimes & 33 & 22 & 66.66 & 1.22 & 0.94-1.59 & 0.188 \\
\hline Never & 244 & 131 & 53.68 & 0.98 & $0.84-1.15$ & 0.820 \\
\hline
\end{tabular}

The reference group is the one with relative risk $=1$.

*total number was 577 as the question was for females only.

to find that $95.5 \%$ of hajjis asked for a new blade before shaving which was similarly found by other studies where the hajjis who got their head shaved with the used razor were only $6 \%$ (Choudhry et al. Behavioural risk factors for diseases during the pilgrimage to Makkah, [unpublished]). This reflects an increase in awareness about the danger of using used blades for head shaving and reduces transmission of blood-borne disease such as HIV, Hepatitis B and C.

\section{Study limitations}

Limitations of this study included the self-reported nature of information collection, and possibly recall bias since some of our recruits were contacted a week post Hajj while others were contacted 4 weeks post Hajj. Also demographic data of nonrespondents were not available to determine if they differed from respondent or not. The strengths of this study included the use of trained interviewers, use of standardized questionnaire and collecting information regarding symptoms rather than disease names, which should reduce variation in participant description. A substantial study size $(\mathrm{n}=1507)$ provided for ample statistical power. While comparing the results of the present study with previous behavioural risk factors studies conducted in 1998, 2002, and $2066[19,20]$ improvements were noticed in some of the variables, such as increase in proportion of hajjis for whom Hamla was the main source of cooked food, for whom sealed plastic bottles/ bags were the main source of drinking water, who get their hair cut by professional barber, who used face mask during hajj, who had both influenza and Hepatitis A vaccination coverage; and decrease in proportion of hajjis who suffered from injuries.

In conclusion, URTI is a common health problem among studied 
domestic hajjis. Generally, there is improvement in the adoption of preventive measures by hajjis, however still face mask use is limited in spite of the fact that using it significantly decreases the risk for URTI.
In recommendations, the surveillance system for URTI need to be enhanced by the Ministry of Health due to its high incidence and the burden it has on health system both in Hajj area and the city of residence of the hajjis
Health education programs should be organized to all those who intended to perform hajj to increase the awareness about protective measures against URTI, diarrhoeal diseases, injuries and exacerbations of chronic diseases.

\section{References}

1. Gatrad AR, Sheikh A. Hajj: journey of a lifetime. BMJ 2005; 330: 133-137.

2. Ahmed QA, Arabi YM, Memish ZA. Health risks at the Hajj. Lancet 2006; 367:1008-1015.

3. Shafi S, Memish ZA, Gatrad AR, Sheikh A. Hajj 2006: communicable disease and other health risks and current official guidance for pilgrims. Euro Surveill2005; 10: E051215.

4. Al-Harthi AS, Al-Harbi M. Accidental injuries during Muslim pilgrimage. Saudi Med J 2001; 22:523-525.

5. Madani TA, Ghabrah TM, Albarrak AM, Alhazmi MA, Alazraqi $\mathrm{TA}$, Althaquafi $\mathrm{AO}$, et al. Causes of admission to intensive care units in the Hajj period of the Islamic year 1424 (2004). Ann Saudi Med 2007; 27:101-105.

6. Khan NA, Ishag AM, Ahmad MS, El-Sayed FM, Bachal ZA, Abbas TG. Pattern of medical diseases and determinants of prognosis of hospitalization during 2005 Muslim pilgrimage Hajj in a tertiary care hospital. A prospective cohort study. Saudi Med J 2006; 27:1373-1380.

7. Rahman MM, Al-Zahrani S, Al-Qattan MM. Outbreak of hand injuries during Hajj festivities in Saudi Arabia. Ann PlastSurg1999; 43: 154-155.

8. Gatrad AR, Sheikh A. Hajj and risk of blood borne infections. Arch Dis Child 2001; 84:375.

9. Yousuf M, Nadeem A. Meningococcal infection among pilgrims visiting Madinah Al-Munawarah despite prior A-C vaccination. J Pak Med Assoc 2000; 50: 184-186.

10. Khan MA. Outbreaks of meningococcal meningitis during Hajj: changing face of an old enemy. J Pak Med Assoc 2003; 53:1-3.

11. Ahmed AM. Care of diabetic patients on the Haj. Diabetes International 2002; 12: 8-9.
12. Yousuf M, Al-Saudi DA, Sheikh RA, Lone MS. Pattern of medical problems among Haj pilgrims admitted to King Abdul Aziz Hospital, Madinah Al-Munawarah. Ann Saudi Med 1995; 15:619-621.

13. Madani TA, Ghabrah TM, Al-Hedaithy MA, Alhazmi MA, Alazraqi TA, Albarrak AM, et al. Causes of hospitalization of pilgrims in the Hajj season of the Islamic year 1423 (2003). Ann Saudi Med 2006; 26:346-351.

14. Al-Ghamdi SM, Akbar HO, Qari YA, Fathaldin OA, Al-Rashed RS. Pattern of admission to hospitals during Muslim pilgrimage (Hajj). Saudi Med J 2003; 24:1073-1076.

15. Choudhry AJ, Al-Mudaimegh KS, TurkistaniAM, Al-Hamdan NA. Hajj-associated acute respiratory infection among hajjis from Riyadh. East Mediterr Health J 2006; 12:300-309.

16. Chin J. Control of communicable diseases manual. 17th ed. Washington (DC): American Public Health Association; 2000.p. 425-425.

17. Pippin DJ, Verderame RA, Weber KK. Efficacy of face masksin preventing inhalation of airborne contaminants. J OralMaxillofacSurg1987; 45:319-323.

18. CDC. Recommendations for the Prevention of Influenza. MMWR 2008; 57:1-60.

19. Al-Fefy S, El-Bushra H, Al-Wehebi S, Al-Salman S, Ba Omer A,Khawaja A, et al. Behavioral risk factors for pilgrims to Makkah,1997. Saudi Epidemiology Bulletin 1998; 5:1-4.

20. Al-Maghderi Y, Al-Joudi A, Chaudhry A, Al-Rabeah A, IbrahimM, Turkistani AM. Behavioral Risk Factors for Diseases duringHajj 1422 H, (2002 G). Saudi Epidemiology Bulletin 2001; 9:19-20. 